\title{
Off-label, off-limits? Parental awareness and attitudes towards off-label use in paediatrics
}

\author{
Christian Lenk • Philipp Koch • Hildegard Zappel • \\ Claudia Wiesemann
}

Received: 22 September 2008 / Accepted: 18 February 2009

(C) The Author(s) 2009. This article is published with open access at Springerlink.com

\begin{abstract}
Off-label drug use in paediatrics is associated with an increased risk of adverse drug reactions. Any riskbenefit analysis has to be based on value judgments that should include parents' views. However, nothing is known so far about the parents' perspective on this critical issue. Therefore, a quantitative survey with parents of healthy and chronically ill children was carried out $(n=94)$. Knowledge about the practise of off-label use is generally poor in both groups. Surprisingly, this is also true for the parents of children with chronic disease. Nine percent of the parents of chronically ill children and $20 \%$ of the parents of healthy children would refuse treatment with an off-label drug. Parents who have poor knowledge about the practise of offlabel use tend to refuse to volunteer their child for study participation. Therefore, the information of parents on the off-label use of drugs is important to meet ethical standards and to increase the parents' acceptance of medical studies with children.
\end{abstract}

Christian Lenk and Philipp Koch contributed equally to this work.

C. Lenk $(\triangle) \cdot$ P. Koch $\cdot$ C. Wiesemann

Department for Medical Ethics and History of Medicine,

University of Göttingen,

Humboldtallee 36,

37073 Göttingen, Germany

e-mail: clenk@gwdg.de

URL: www.gwdg/ clenk

H. Zappel

Department for Paediatrics II, University of Göttingen,

Robert-Koch-Str. 40,

37075 Göttingen, Germany
Keywords Ethics · Off-label use · Parents . Informed consent $\cdot$ Risk assessment

\section{Introduction}

The off-label use of drugs in paediatrics, i.e. the prescription of drugs which are not licensed for a specific age or mode of application, is often described as an ethical problem $[1-3,6,10]$. Children with chronic renal insufficiency, for example, often suffer from arterial hypertension. They need long-term antihypertensive therapy with drugs which, however, are not approved for children so far. Drugs of first choice are angiotensin-converting enzyme inhibitors: captopril, enalapril and ramipril. Since clinical trials involving children do not exist, the applied dosage results from experience with adults. Empirical studies show that the off-label use of drugs in paediatrics is connected with a significantly increased risk of an adverse drug reaction [11, $16,19]$. This is due to the fact that these drugs are only tested in and licensed for adult patients and the transfer of knowledge to the paediatric population is sometimes doubtful. As Collier argues, "The validity of such an approach is questionable because there are such great differences between adults and children, and even between children of different ages, with regard for instance to the pharmacodynamic and pharmacokinetic responses to drugs, [...], and the effects of drugs on normal growth and development" [6: p. 6]. There is a high incidence of offlabel use both in out-patient and in-patient settings, which ranges from $10.5 \%$ up to $90 \%[4,8,15]$. Off-label use is so commonplace that it is often probably not specifically mentioned when a drug is administered to a patient.

At least two ethical problems arise from this: first, if the off-label use of drugs can be understood as a form of 
unconventional treatment which comprises unknown risks, the question arises whether parents should explicitly be informed about the character of the treatment. ${ }^{1}$ Here, a difficulty arises due to the fact that even some paediatricians are not aware of the practise of off-label prescriptions. In a study of Chalumeau et al., French paediatricians were asked to comment whether their prescriptions were off-label or not. In $92 \%$ of the cases, the paediatricians did not recognise a drug's off-label status [5]. Secondly, the ethical principle of non-maleficence calls for a reduction of risks in the course of a medical treatment wherever possible. This is particularly important in the case of vulnerable groups like children [13, 14]. To minimise the number of off-label treatments, one could either leave patients untreated or increase the number of clinical trials in the paediatric population, either way entailing severe ethical problems involving complex risk-benefit analyses. However, so far, no systematic knowledge is available on the preferences of parents in these cases. Do they accept offlabel use as inevitable or as the lesser of two evils? Would they volunteer their child for clinical trials to reduce the incidence of off-label treatments? As paediatricians have a reputation for being cautious in relation to burdening their little patients with clinical research, parents' views would help to evaluate the pros and cons of yet another trial in the paediatric population.

To come to know parents' views on off-label use, we conducted an empirical survey with parents of chronically sick and healthy children. We assumed that members of both groups differ with regard to knowledge and evaluation of this phenomenon, dependent on the degree of previous clinical experience. While parents of healthy children represent the 'normal' population and their typical level of knowledge and normative judgments, parents of chronically ill children may have achieved a kind of 'expert status' and thus extensive knowledge about medical treatment. We also assumed that parents of ill children differ in weighing risks and benefits in treatment as well as in clinical studies with their children.

\section{Methods}

In a first step, we developed a questionnaire on ethical aspects of off-label use in paediatrics in close collaboration with experienced paediatricians and parents of chronically ill children. The questionnaire comprised three different

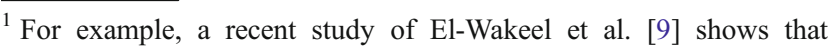
patients are very interested in information regarding possible treatment risks and complications before giving informed consent.
}

sections: First, we asked questions concerning the demographic facts, the family's and children's actual health condition as well as their experience in clinical studies. In the second part, we explored parental knowledge and views of off-label use in paediatrics. Finally, the parents had to assess whether they would volunteer their children for participation in three different study scenarios. We assumed that the answers depended on parental educational status, the health condition of the child and experience with clinical trials. We were particularly eager to know whether the actual knowledge of parents about off-label use has an influence on the overall acceptance of off-label treatment or study participation. Fishers' exact test was used to analyse associations in non-parametric categorical data. Statistical significance is defined by a $p$ value $<0.05$. The study was approved by the Research Ethics Committee of the University of Göttingen.

\section{Participants}

Parents of children with renal disease (group A) were contacted via the Departments for Paediatrics at Göttingen and Hanover University Hospitals in Lower Saxony. According to the studies of Conroy et al. [7] and Knöppel et al. [12], one can expect that between $31 \%$ and $67 \%$ of the prescriptions in such a medical setting will be off-label. We distributed 80 questionnaires to parents visiting out-patient care in the time from June to September 2006 and received back $43(54 \%)$. Inclusion criteria were the age of children (6 to 14 years), the length of contact with the hospital (at least a half year) and the chronic state of the treated condition. Children had a great variety of renal conditions including milder forms of renal disease, renal insufficiency and renal transplant. During routine hospital visits, parents were informed by a consultant about the study and asked to participate. They received the questionnaire and were asked to send it back. The parents of healthy children (group B) were contacted at a soccer club meeting in the city of Kassel. For the control group, we chose parents from children playing soccer in a club because these children are normally healthy and need only minor health care interventions. In Germany, children who play soccer have to pass a health test before joining the club. Moreover, soccer in Germany is an all-class sport. We thus expected parents to represent a broad educational background. Again, 80 questionnaires were distributed to this group and 51 (64\%) were sent back. Children of these parents were members of the club and in good health condition. Fifteen $(30 \%)$ of the parents from group B reported some common but minor chronic disease conditions (mostly asthma and neurodermitis) in their families (Table 1). 
Table 1 Participants, contact and number of returns

\begin{tabular}{lclll}
\hline $\begin{array}{l}\text { Study } \\
\text { group }\end{array}$ & Participants & Contact & $\begin{array}{l}\text { Requested } \\
\text { persons }\end{array}$ & $\begin{array}{l}\text { Number } \\
\text { of returns, } \\
n(\%)\end{array}$ \\
\hline Group A & $\begin{array}{c}\text { Parents of } \\
\text { children } \\
\text { with renal } \\
\text { disease }\end{array}$ & $\begin{array}{c}\text { Contact via } \\
\text { Göttingen/ } \\
\text { Hanover } \\
\text { University }\end{array}$ & 80 & $43(54)$ \\
Group B & $\begin{array}{c}\text { Parents of } \\
\text { healthy } \\
\text { children }\end{array}$ & $\begin{array}{c}\text { Contact via } \\
\text { soccer club }\end{array}$ & 80 & $51(64)$ \\
\hline
\end{tabular}

\section{Results}

In group A (chronically ill children), the mean age of the sick children was 9.9 years. Asked how often they usually see a doctor, eight parents (19\%) reported 'one or more visits per week' and 15 parents (35\%) 'once a month'. Eleven parents (26\%) reported only 'irregular' health contacts. Health care was in most cases delivered by a paediatrician $(22 / 51 \%)$ or a university hospital $(23 / 54 \%)$. Nine children (21\%) of group A had already been included in one or more clinical studies. Parents' educational status was comparable to the German population as eight parents $(19 \%)$ hold a university degree or finished school with the final secondary school examination, 29 parents (67\%) with the intermediate secondary school examinations and six parents $(14 \%)$ with the lower secondary school examinations. In group B (healthy children), the children's mean age was 9.5 years, and the parents' educational level was higher than in the group A with 26 parents (51\%) holding a university degree or finishing school with the final secondary school examination, 25 parents (49\%) with the intermediate secondary school examinations and none with the lower secondary school examinations. In both groups, questionnaires were mainly completed by the children's mothers $(79 / 84 \%)$.

\section{Parents' knowledge of drug use (Table 2)}

The parents in both groups A and B showed great interest in information on the mode of application and on possible side effects of prescribed drugs. None out of group A and only five out of group B $(5 \%, n=94)$ answered that they usually do not ask their physician for additional information on the usage, mode of action or possible side effects of prescribed drugs $(p=0.04)$. In groups $\mathrm{A}$ and $\mathrm{B}$, no parent answered that she/he does not read leaflet instructions of a newly prescribed drug. Twenty-two $(23 \%, n=94)$ answered that they 'sometimes' read the leaflet instruction, the remaining $72(77 \%, n=94)$ answered that they 'always'
Table 2 Questions concerning the parental knowledge of drug use

Do you ask for the mode of application or action and possible side effects when the physician prescribes a drug to your daughter/son? (No/Yes, namely ...)

Do you read the instruction leaflet before you give your child a prescribed drug? (Never/Sometimes/Always/Remarks: ...)

Does your physician draw your attention to possible side effects of a prescribed drug? (Never/Sometimes/Always/Remarks: ...)

read the instruction. Additionally, 39 parents of group A (91\%) and 43 parents (84\%) of group B indicated that their physician 'sometimes' or 'always' draws their attention to possible side effects of a prescribed drug.

Knowledge and evaluation of off-label use of drugs (Table 3)

The parents' wish for information about prescribed drugs stands in stark contrast to their actual knowledge of the practise of off-label use. In group B (healthy children), only 14 parents (28\%) were aware that children are sometimes administered drugs which are not tested and licensed for, one third $(17 / 33 \%)$ were convinced that this is not the case and 20 parents (39\%) admitted that they do not know (Fig. 1). One may not be surprised by such a ratio in group $\mathrm{B}$; however, in contrast to our initial assumption, we found a similar low level of parental awareness in group A. In this group, 15 parents $(35 \%)$ were aware of the practise of offlabel use in contrast to 11 parents $(26 \%)$ who thought that this was not the case and 16 parents (37\%) who answered 'I do not know' (no statement $=1 / 2 \%$ ). The results show that only a small additional percentage of parents of ill children compared to the parents of healthy children have acquired knowledge about the off-label use of drugs. No statistically significant difference could be demonstrated between groups $\mathrm{A}$ and $\mathrm{B}$ concerning the parental knowledge on the off-label use of drugs.

Would knowledge of an off-label use of drugs influence parents' consent to treatment or would they consider this information as not being important? In both groups, all of the 94 participants accorded some importance to the fact

Table 3 Questions concerning the knowledge of off-label use of drugs

Please judge the following statements concerning drugs for children. Do you think they are right or wrong?

-Drugs for children are different from drugs for adults regarding dosage, degree of effectiveness and mode of action in the body. (Yes/No/Do not know)

-Children sometimes receive drugs which are not tested and licensed for them. (Yes/No/Do not know) 
that a drug is licensed or not. Four parents ( $9 \%$ ) of group A and ten parents $(20 \%)$ of group B would even refuse a treatment with off-label drugs. Thirty-one parents $(72 \%)$ of group A and 26 parents (51\%) of group B would agree 'when there is no other possibility'. Eight parents (19\%) of group A and 15 parents (29\%) of group B specified conditions of consent like, e.g. 'a life-threatening condition' or 'only in extreme situations'. One parent of a healthy child remarked that such a decision would be 'very hard and depends on the situation'. Although the difference between both groups is statistically not significant $(p=$ 0.11 ), risk aversion, measured as percentage of refusal of off-label use, seems to be higher among the parents of healthy children (group B) than among the parents of ill children (group A) (Fig. 2; Table 4).

\section{Acceptance of different types of clinical studies}

In the third section of the questionnaire, we presented different research scenarios and asked for parental consent. The scenarios of clinical studies were described in a short, simple and easily comprehensible way. Three types of clinical studies were represented (Table 5).

To assess whether parents are willing to volunteer their child - in case of illness - for a clinical study, they had to evaluate three different study scenarios with varying levels of risk. The results show significant differences between groups A and B regarding studies 1 (add-on scenario) and 2 (placebo trial), and a comparable outcome in study 3 (optimization study). Whereas almost half of the parents in group A $(21 ; 49 \%)$ would agree to their child's participation in study 1 (add-on), this was the case in only $11(22 \%)$ of parents of group B. Correspondingly, ten parents $(23 \%)$ of

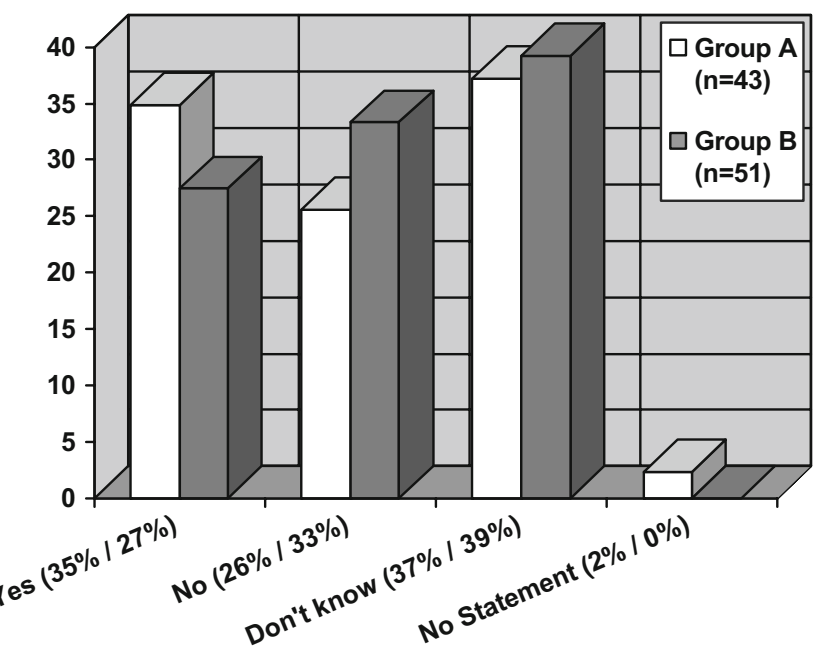

Fig. 1 'Children sometimes receive drugs which are not tested and licensed for them.' (Group A parents of ill children, Group B parents of healthy children)
Table 4 Questions regarding the evaluation of off-label use of drugs

To which of the following statements would you agree?

-I would refuse the treatment of my child with a drug which is not licensed, even when there is no other possibility.

-I would agree to the treatment of my child with a drug which is not licensed, when there is no other possibility.

-It is not important for me, whether a prescribed drug is licensed or not.

-Remarks: ...

group A and 20 parents $(39 \%)$ of group B would refuse participation; 12 parents (28\%) of group A and 20 parents $(39 \%)$ of group B answered that they did not know how to decide $(p=0.02)$. The second study scenario (placebo) was evaluated comparably in group A (yes $=20 / 47 \%$; no $=11$ / $26 \%$; do not know $=12 / 28 \%$ ). Parents of group B, however, were more critical. Only ten parents $(20 \%)$ of group B would consent to study participation, while 28 parents $(55 \%)$ would refuse. One in four $(13 / 26 \%)$ of the parents of group $\mathrm{B}$ did not know how to decide. The difference between groups A and B was statistically highly significant ( $p=0.006$ ). The evaluation of the third study (optimization) showed less remarkable differences. While 17 parents $(40 \%)$ of group A would volunteer their child, 12 parents (28\%) would refuse and 14 parents $(33 \%)$ did not know how to decide. The results are comparable to those of group B (yes $=19 / 37 \%$; no $=20 / 39 \%$; do not know $=12 / 24 \%$; $p=$

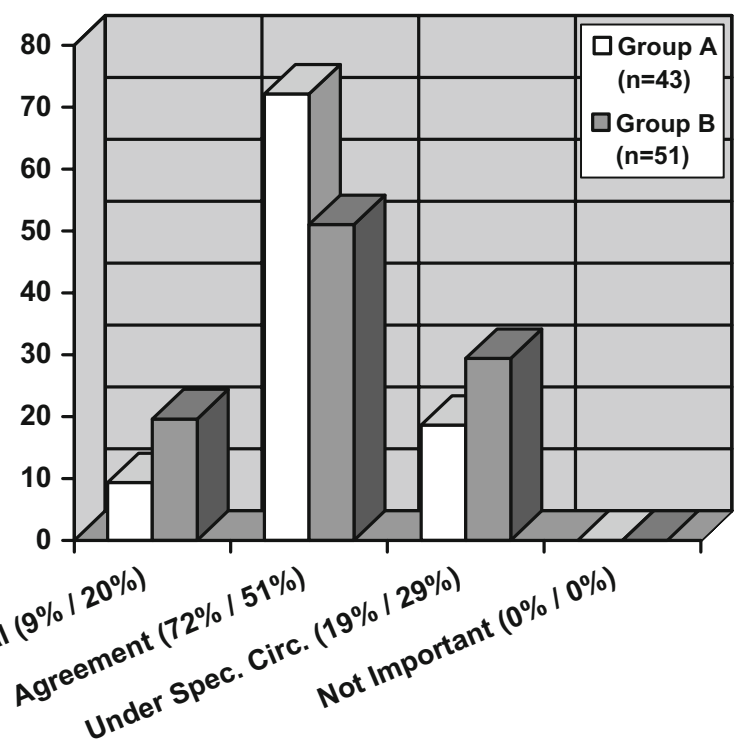

Fig. 2 'I refuse/agree/agree under special circumstances to the treatment of my child with an unlicensed drug when there is no other possibility./It is not important for me, whether a prescribed drug is licensed or not.' (Group A parents of ill children, Group B parents of healthy children) 
Table 5 Types of clinical studies portrayed in the questionnaire

Types of clinical studies

(1) Randomised, double-armed add-on study (standard therapy vs. standard therapy plus one additional drug); additional blood and urine samples for research purposes.

(2) Randomised, double-armed placebo study (newly tested drug vs. placebo); additional blood and urine samples for research purposes.

(3) Optimization study; test in a paediatric population of a drug which is already licensed in adult patients; additional blood and urine samples for research purposes.

0.45). Thus, in group A, most parents would consent to the add-on scenario, while scenario 3 (optimization) met the least acceptance. Parents of healthy children (group B), in contrast, considered the optimization scenario the most acceptable one and were most negative in the case of the placebo scenario (Fig. 3).

Parents who would volunteer their child for either study did not significantly differ from their more critical counterparts with regard to educational status or gender. However, although statistically not significant, there are some clues why some parents are less cautious towards study participation. For the sake of analysis, we made up three categories: in the first category ('supporters'), we subsumed all parents who consented to study participation in at least two scenarios (32 parents); in the second category ('indifferents'), those who answered 'I do not know' in at least two cases (30 parents); in the third category ('refusers'),

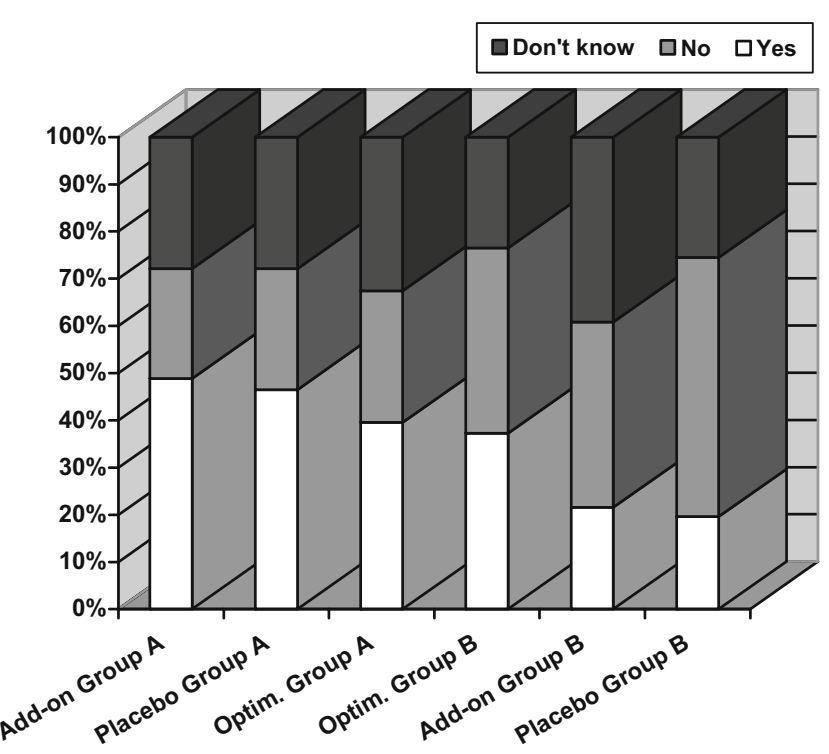

Fig. 3 'Your child suffers from chronic disease. Would you volunteer your child for the following study?' Answers according to decreasing acceptance those who rejected study participation in at least two study scenarios (32 parents). Fifteen parents of the supporters $(47 \% ; n=32)$ answered that their physician always informs them about a drug's possible side effects, whereas only eight $(27 \% ; n=30)$ of the indifferent parents and nine $(28 \%$; $n=32)$ of the refusers reported this fact $(p=0.19)$. Fourteen $(44 \% ; n=32)$ of the supporters knew that children receive prescribed drugs which are not tested and licensed for them compared to only seven $(24 \% ; n=30)$ of the indifferent parents and eight $(25 \% ; n=32)$ of the refusers $(p=0.2)$. Moreover, the group of supporters comprised the highest number of parents $(30 / 94 \% ; n=32)$ who felt that the offlabel use of drugs is acceptable 'when there is no other possibility' compared to only $24(75 \% ; n=32)$ of the refusers (Fig. 4).

\section{Conclusions}

The results of our study show that knowledge of the offlabel use of drugs in paediatrics is rather limited and astonishingly low — regarding the importance of this topicin both groups of parents of chronically ill and healthy children. Only $31 \%$ of the parents $(35 \%$ in group A and $28 \%$ in group B) knew about the practise of off-label prescriptions whereas $70 \%$ were convinced that this was not the case or were at least unsure about the fact. Regular contact to health care providers had no substantial effect on this ratio. This may in part be due to bad memory; however, all parents declared to actively seek for information on drugs administered to their child, as all of them stated to read the leaflet instruction and nearly all of them remembered their physician telling them about side effects. It is difficult to explain the low percentage of informed

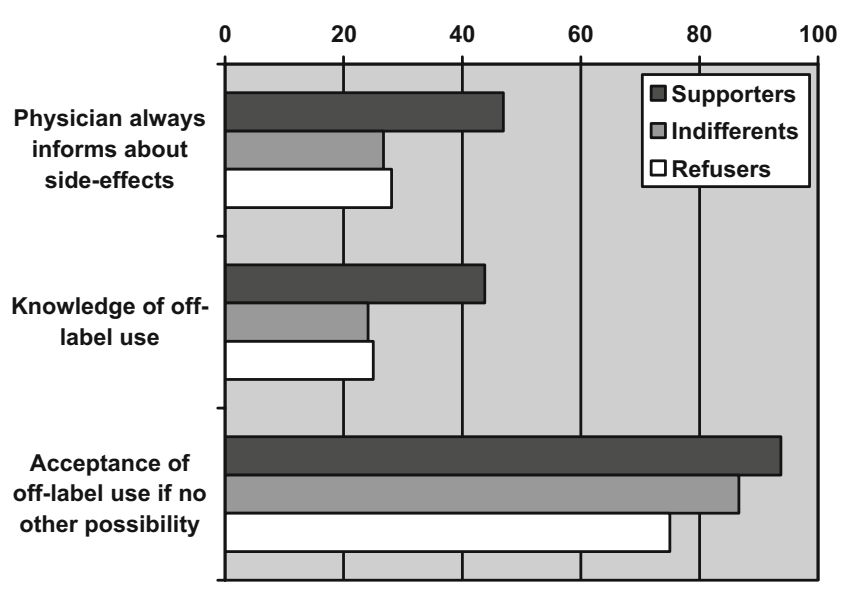

Fig. 4 Information on side effects, knowledge of off-label use and acceptance of off-label use in case of no other treatment possibility in percent of study supporters, indifferent and refusing parents 
parents particularly in the group of chronically ill children where one would expect the hospital paediatricians to have drawn parents' attention to the fact of off-label use. Information about off-label use is not legally required but only recommended by lawyers in Germany and it is not known how often physicians follow this recommendation $[17,18]$. The information was possibly not made available often enough. Paediatricians themselves may get used to the fact, as off-label prescription is so common, and may forget about informing parents explicitly and repeatedly. Some paediatricians might themselves not be fully informed about the off-label status of the drugs they prescribe.

Once given the information, parents have a distinctive view of the off-label use of drugs. A significant percentage of parents of healthy and chronically ill children $(15 \%)$ would refuse the use of these drugs, even when there is 'no other possibility', and a large group of parents (25\%) would agree to the off-label use of drugs only under certain conditions like a life-threatening disease. Given the importance of parents' values in medical decision making, our results illustrate why the practise of downplaying offlabel use in the paediatric population and keeping parents uninformed about the existence of off-label use in paediatrics is ethically problematic. Off-label use is the result of a risk-benefit analysis and thus depends on value judgments parents are willing and prepared to be involved in. Moreover, our study results hint at the fact that the wellinformed parent might be more willing to volunteer their child for study participation and thus help to reduce the high incidence of off-label administration of drugs. A large group of parents $(52 \% ; n=49)$ of either sick or healthy children in our sample consent to participation in at least one of the described study scenarios. Among the parents of chronically ill children in our study, the add-on study scenario received the highest grade of acceptance $(49 \% ; n=$ 21). The readiness to accept clinical research was associated with parental knowledge of off-label use and a perceived general tendency of the paediatric consultant to inform about the side effect of drugs. If paediatricians want investigators and pharmaceutical companies to provide them with more scientific evidence on drug therapy, they may have to inform parents first. This may well help to find patients for the studies that have to be conducted in the next years.

Acknowledgements We would like to thank Mr. Nils Hoppe, MRI LL.B. for the linguistic editing of this manuscript.

Conflict of interests The authors declare that they have no conflict of interest. This study was not sponsored by any external organisation.

Open Access This article is distributed under the terms of the Creative Commons Attribution Noncommercial License which permits any noncommercial use, distribution, and reproduction in any medium, provided the original author(s) and source are credited.

\section{References}

1. Askin DF (2006) Off-label therapies for newborns: miracles or mistakes? AWHONN Lifelines 10(2):160-162

2. Atkins CD (1998) Ethics of off-label treatment. J Clin Oncol 16:365-366 discussion 366-371

3. Bonati M, Choonara I, Hoppu K et al (1999) Closing the gap in drug therapy. Lancet 353:1625. doi:10.1016/S0140-6736(05) 75752-4

4. Buecheler R, Schwab M, Moerike K et al (2002) Off label prescribing to children in primary care in Germany: retrospective cohort study. BMJ 324:1311-1312. doi:10.1136/bmj.324. 7349.1311

5. Chalumeau M, Tréluyer JM, Salanave B et al (2000) Off label and unlicensed drug use among French office based paediatricians. Arch Dis Child 83:502-505 here: 503

6. Collier J (1999) Paediatric prescribing: using unlicensed drugs and medicines outside their licensed indications. J Clin Pharmacol 48:5-8. doi:10.1046/j.1365-2125.1999.00983.x

7. Conroy S, Choonara I, Impicciatore P et al (2000) Survey of unlicensed and off label drug use in paediatric wards in European countries. European Network for Drug Investigation in Children. BMJ 320:79-82

8. Conroy S, McIntyre J, Choonara I (1999) Unlicensed and off label drug use in neonates. Arch Dis Child Fetal Neonatal Ed 80:F142F145

9. El-Wakeel H, Taylor GJ, Tate JJ (2006) What do patients really want to know in an informed consent procedure? A questionnairebased survey of patients in the Bath area, UK. J Med Ethics 32:612-616. doi:10.1136/jme.2005.013334

10. European Medicines Agency (EMEA) (2004) Evidence of harm from off label or unlicensed medicines in children. London 2004. Available at http://www.emea.eu.int

11. Gill AM, Leach HJ, Hughes J et al (1995) Adverse drug reactions in a paediatric intensive care unit. Acta Paediatr 84:438-441. doi:10.1111/j.1651-2227.1995.tb13667.x

12. Knoeppel C, Klinger O, Soergel M et al (2000) Anwendung von Medikamenten außerhalb der Zulassung oder ohne Zulassung bei Kindern. Monatsschr Kinderheilkd 148:904-908. doi:10.1007/ s001120050670

13. Lenk C, Radenbach K, Dahl M, Wiesemann C (2004) Nontherapeutic research with minors: how do chairpersons of German research ethics committees decide? J Med Ethics 30:85-87. doi:10.1136/jme.2003.005900

14. Marcovitch H (2005) Safer prescribing for children. BMJ 331:646-647. doi:10.1136/bmj.331.7518.646

15. McIntyre J, Conroy S, Avery A et al (2000) Unlicensed and off label prescribing of drugs in general practice. Arch Dis Child 83:498-501. doi:10.1136/adc.83.6.498

16. Neubert A, Dormann H, Weiss J et al (2004) The impact of unlicensed and off-label drug use on adverse drug reactions in paediatric patients. Drug Saf 27:1059-1067. doi:10.2165/ 00002018-200427130-00006

17. Poetsch J (2006) Juristisches Spannungsfeld bei der Off-LabelVerordnung von Arzneimitteln in der Pädiatrie. JDDG 5:421-426 here: 423

18. Schwarz JA, Bass R, Holz-Slomczyk M et al (1999) Therapieversuche mit nicht zugelassenen Prüfsubstanzen (Compassionate Use) und zugelassenen Arzneimitteln (Off-Label Use). Pharm Ind 61:309-314 here: 314

19. Turner S, Nunn AJ, Fielding K, Choonara I (1999) Adverse drug reactions to unlicensed and off-label drugs on paediatric wards: a prospective study. Acta Paediatr 88:965-968. doi:10.1080/ 08035259950168469 